Original Research Paper

\title{
Study on Sero-Prevalence of Small Ruminant and Human Brucellosis in Yabello and Dire Districts of Borena Zone Oromia Regional State, Ethiopia
}

\author{
Wubishet Zewdie \\ Oromia Pastoralist Area Development Commission Yabello Regional Veterinary Laboratory, P.O Box 169, Yabello, Ethiopia
}

\author{
Article history \\ Received: 03-10-2019 \\ Revised: 19-12-2019 \\ Accepted: 21-01-2020 \\ Email: wubevet1921@gmail.com \\ wubenbe2122@gmail.com
}

\begin{abstract}
Cross-sectional study was conducted in Yabello and Dire districts of Borena zone Oromia regional state, Ethiopia to estimate seroprevalence of small ruminant and human Brucellosis. Sero-survey was applied to the target population of 228 small ruminants and 86 humans. The sera samples were collected from small ruminants (sheep and goats) and humans for serological analysis of brucellosis. Samples were serially tested by RBPT and positive samples were finally confirmed by c-ELISA. The overall sero-prevalence of brucellosis were $8.8 \%$ (95\% CI: 5.4-13.2) and $25.6 \%$ (95\% CI: 16.8-36.1) in small ruminants and humans respectively. There was a statistically significant variation in Brucella infection $(\mathrm{p}<0.05)$ in humans. The higher prevalence recorded in elders. The highest recorded in small ruminant sampled from large flock size and ewes with a retained fetal membrane. These results provide evidence of the importance of brucellosis in humans and small ruminants in the study area. Overall, the existence of brucellosis, community daily practice and uncontrolled movement of animals and livelihood nature of pastoralists suggest the need for farther investigation of brucellosis in humans and animals. Furthermore, awareness creation or public health education on zoonotic importance of brucellosis and prevention techniques should be imparted continuously in pastoral communities.
\end{abstract}

Keywords: Brucella, ELISA, RBPT, Zoonotic

\section{Introduction}

Brucellosis is a worldwide zoonosis with a high degree of morbidity in humans. According to WHO about 500,000 human cases of this disease registered in the world every year (Pappas et al., 2006). Recent estimates from East Africa suggest that there are approximately 21 million brucellosis cases in livestock annually (McDermott and Arimi, 2002).

Livestock industry plays an important role in the economy of the country. In addition, human life is highly associated with the livestock populations in the different livestock production systems particularly in pastoral communities (Megersa et al., 2011). In both pastoral and mixed (agro-pastoral) livestock production systems, people haves contacts with livestock and livestock products/discharges and consume raw animal products. This could enhance the incidence of brucellosis infection (Habtamu et al., 2015; Terefe et al., 2017).
Brucellosis in human is common in rural areas because of farmers or pastoralists live in close contact with their animals and often consume fresh unpasteurized dairy products due to a lack of awareness about zoonotic importance of disease and way of transmissions (Terefe et al., 2017; Mantur and Amarnath, 2008; Amenu et al., 2010; Zeru et al., 2016; Tsegay et al., 2017). The threat of zoonotic diseases for humans is high; brucellosis is the one affecting both humans and livestock.

Infected animals are left unknown and become a source of diseases for humans and continued transmitting diseases. Among several zoonotic diseases affecting humans and animals, brucellosis is known to be an important zoonosis and economically important disease posing considerable cause of reproductive losses in animals (Terefe et al., 2017). Therefore, this study was designed to study seroprevalence and associated risk factors of brucellosis in small ruminants and humans in the study area. 


\section{Materials and Methods}

\section{Description of the Study Area}

The small ruminants and humans Brucellosis study was conducted in Yabello and Dire districts. Yabello and Dire districts are agro-ecologically lowlands and midland areas with an elevation ranging from 11001857 meters above sea level (masl). The average annual rainfall ranges from $300-700 \mathrm{~mm}$ mainly received in long the rainy season (ganna) from AprilJune and a short rainy season (Hagayya) from September-November.

In the area, pastoral livestock production system with mobility is the vital source of food and income for livelihood of people while opportunistic cultivation is practiced around Yabello and Mega Towns where the soil moisture content stays high for longer time. Relatively the altitude of Dire district is higher with moderate production of grains when sufficient rain is available. As a result farming practice is common around Mega Town of Dire district other remaining Kebeles (Pastoral Associations) are pastoralist with sedentary, transhumant and Migrant pastoralist. Dire district make international border with Kenya (Fig. 1).

\section{Study Design and Population}

A cross-sectional study was conducted on a total of 228 small ruminants and 86 human sera to estimate the prevalence of brucellosis and associated risk factors. All sera samples were collected from occupationally associated animal attendants/pastoralists. Case-control sampling techniques were applied to collect the sample from small ruminants. The animals were grouped depending on age, sex, abortion history, retained fetal membrane and other clinical signs (epididymitis and orchitis) in males. Age determination and history for the presence or absence of reproductive problems were obtained from the owners and the animal attendants. After grouping animals accordingly, samples were collected randomly from each group. This technique applied due to high abortion reported in the study area to control the high number of ewes sampling with abortion history. Based on literature (Solomon et al., 2006) and community knowledge flock size was the group into three; Large, Medium and small based on the number of animals in the flock.

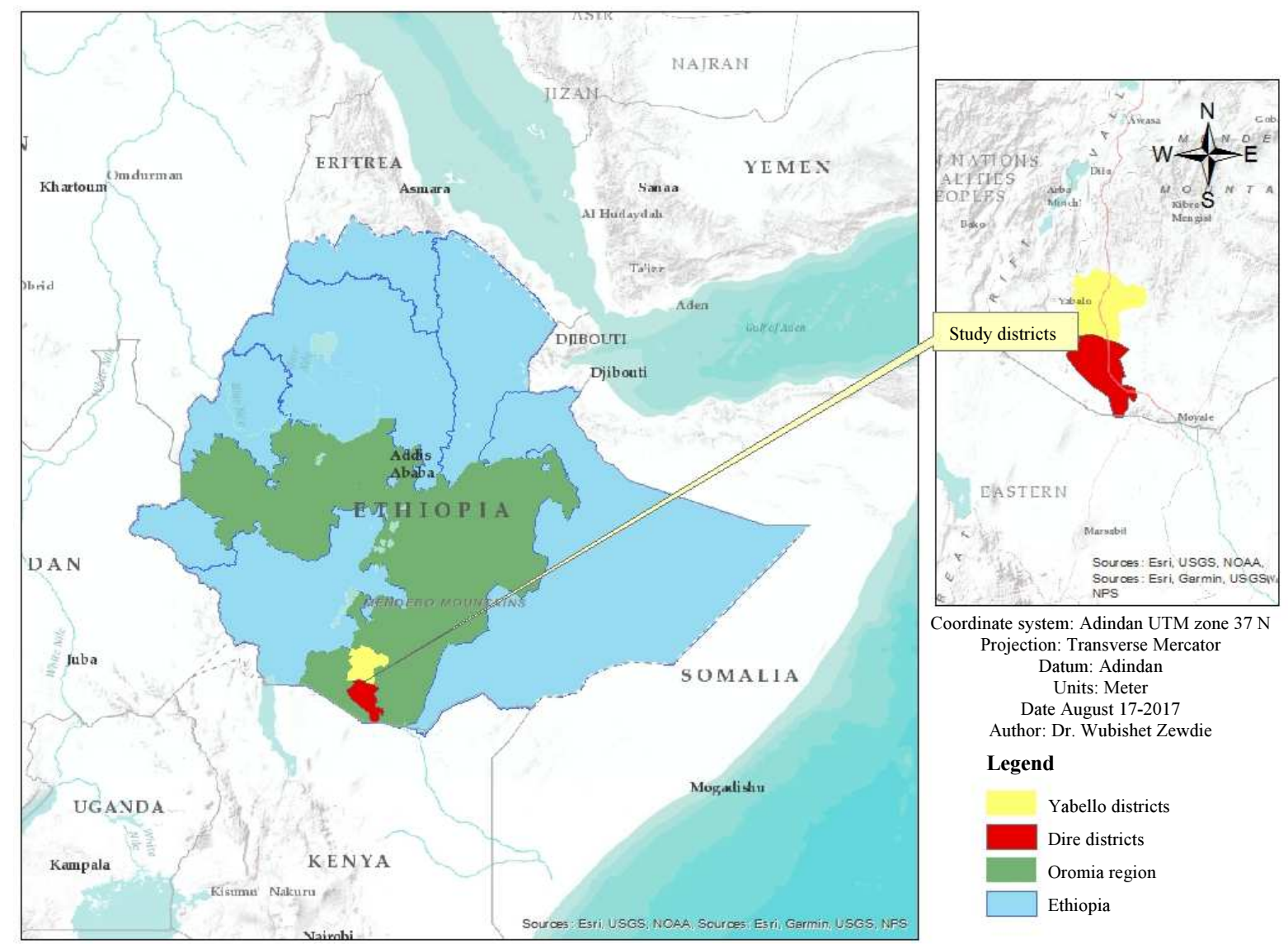

Fig. 1: Map of study area 
Number of shoats greater than $30(>30)$, number of shoats greater than $10(>10)$ but less than thirty $(<30)$ and number of shoats less than or equal to ten $(\leq 10)$; and named as large, medium and small flock size respectively. In addition, attendants/pastoralists were interviewed using a structured questionnaire to collect demographic, epidemiological and clinical data of both small ruminant and human Brucellosis. The population male in the flock is few in number because the male mostly sold only few ram remain for breeding purpose.

\section{Type of Sample and Sampling Procedure}

Before sample collection first, the purpose of the study was explained and consent to participate in the study was obtained from individuals or their parents and guardians. About $10 \mathrm{~mL}$ of blood samples were collected from the jugular vein of each selected animal using plain vacutainer tubes after disinfecting the area by $70 \%$ alcohol. From volunteer animal attendants/pastoralist, about $5 \mathrm{~mL}$ blood sample was collected by a trained medical laboratory technologist. The collected blood samples of animal and human were transported to Yabello Regional Veterinary Laboratory (YRVL) and Yabello Hospital respectively for serum separation, storage, and testing. Serum was removed from the vacutainer tube with a sterile pipette into cryovial and then code on a vacutainer tube registered properly onto cryovial tubes. Finally, the serum kept in $-20^{\circ} \mathrm{C}$ fridges until it tested by RBPT at Yabello Regional Veterinary Laboratory and Yabello hospital. Positive sample for Rose Bengal Plate Test was submitted to National Animal Health Diagnostic and Investigation Center for c-ELISA.

\section{Laboratory Techniques}

\section{Rose Bengal Plate Test}

All serum samples were initially screened using a modified Rose Bengal Plate $(25: 75 \mu \mathrm{L}$, sera: antigen ratio) Test (RBPT) for small ruminants whereas, Rose Bengal Plate Test (RBPT) of 30:30 $\mu \mathrm{L}$ ratio (antigen: serum ratio) was used for humans. The small ruminant samples were tested at Yabello regional veterinary laboratory whereas human samples were tested at Yabello Hospital according to the procedures described (OIE, 2004), the World Organization for Animal Health (Shimeles, 2008).

\section{Competitive ELISA (C-ELISA)}

All serum samples found to be positive by RBPT was tested by C-ELISA. The test conducted according to manufacturer guidelines/SOP.

\section{Data Management and Analysis}

Factors thought to be associated with the epidemiology of brucellosis in small ruminants and humans were recorded in a Microsoft Excel ${ }^{\circledR}$ Spread Sheet. Information like reproductive problems, age of animals and parity numbers were obtained from animal owners/attendants. Data on individual person/ human sex, age, way of consumption of the animal product, methods of handling aborted fetus, means of supporting animals during parturition were also captured. STATA software version 11.0 (CRC Press LL.C2004 UK) for windows was used to analyze the data. A multivariable logistic regression model was used to identify risk factors associated with Brucella infection and Odd Ratio (OR) used to indicate the strength of risk factors associated with a 95\% confidence interval. Descriptive and analytic statistics were also computed using software SPSS Version 15(SPSS Inc. () 2006 USA) and cross-tabulation were employed to see the association of determinant factors (habit of consumption of a raw animal product, handling aborted fetus by bare hand) with that of knowledge of the community about the disease.

\section{Result}

\section{Serological Result}

Out of 228 small ruminants and 86 human sera screened by RBT 21(9.2) and 35(40.7\%), respectively, were found to be positive. With subsequent serial testing, the overall prevalence of brucellosis was $8.8 \%$ (95\% CI: 5.4-13.2) and 25.6\% (95\% CI: 16.7-36.1), in small ruminant and human respectively by c-ELISA. In large flock size and ewes with history of retained fetal membrane, small ruminant brucellosis is higher with significant variation $p$-value less than 0.05 $(\mathrm{p}<0.05)$ (Table 1).

In human, Brucellosis is higher in individuals with a history of contact with retained fetal membrane and age greater than 55 years old with significant statistically variation $(\mathrm{p}<0.05)$ (Table 2$)$.

\section{Questioner Result}

Pastoralists recognize abortion in their animals and call "sallassu" (abortion) (local language Afaan Oromo). The community consume aborted ewe milk by stimulation/forcing ewes to give milk after abortion called "Backisu" which could be the risk factor for transmission of disease from carrier animals. There were different community practices which thought to be risk factors associated with occurrence of disease in humans. Community practices involves, handling aborted fetus and aborted materials (Placenta) by bare hand; drinking of raw milk and blood including milk from aborted ewes. 
Table 1: Multivariable logistic regression analysis of small ruminant brucellosis prevalence relative to different factors by c-ELISA

\begin{tabular}{|c|c|c|c|c|c|}
\hline Factors & No & No positive (\%) & Odds Ratio & $\mathrm{P}>|\mathrm{z}|$ & 95\% Conf. Interval \\
\hline \multicolumn{6}{|l|}{ Flock size } \\
\hline Large & 59 & $11(18.6)$ & 15.10 & 0.011 & 1.912 .1 \\
\hline Medium & 101 & $8(7.9)$ & 5.60 & 0.108 & $0.68-45.9$ \\
\hline Small & 68 & $1(1.5)$ & & & \\
\hline \multicolumn{6}{|l|}{ Species } \\
\hline Goat & 144 & $15(10.4)$ & 1.50 & 0.458 & $0.54-3.9$ \\
\hline Sheep & 84 & $5(6.0)$ & & & \\
\hline \multicolumn{6}{|l|}{ Still birth } \\
\hline Ewes with still birth & 11 & $2(18.2)$ & 2.50 & 0.265 & $0.49-12.5$ \\
\hline No still birth & 208 & $17(8.2)$ & & & \\
\hline \multicolumn{6}{|l|}{ Abortion History } \\
\hline Ewes with abortion & 20 & $16(8.0)$ & 2.00 & 0.301 & $0.53-7.6$ \\
\hline No abortion & 199 & $3(15.0)$ & & & \\
\hline \multicolumn{6}{|l|}{ Retained placenta } \\
\hline Ewes with retained FM & 10 & $5(50.0)$ & 13.90 & 0.000 & $3.6-53.8$ \\
\hline No retained FM & 209 & $14(6.7)$ & & & \\
\hline \multicolumn{6}{|l|}{ District } \\
\hline Arero & 78 & $4(5.1)$ & 0.35 & 0.085 & $0.10-1.2$ \\
\hline Dire & 76 & $6(7.9)$ & 0.55 & 0.270 & $0.19-1.6$ \\
\hline Yabello & 74 & $10(13.5)$ & & & \\
\hline \multicolumn{6}{|l|}{ Sex } \\
\hline Male & 9 & $1(11.1)$ & 1.30 & 0.815 & $0.15-10.9$ \\
\hline Female & 219 & $19(8.7)$ & & & \\
\hline
\end{tabular}

Table 2: Multivariable logistic regression analysis of human brucellosis prevalence relative to different factors by c-ELISA

\begin{tabular}{|c|c|c|c|c|c|c|}
\hline \multirow[b]{2}{*}{ Factors } & & \multicolumn{4}{|c|}{ Competitive ELISA(c-ELISA) } & \multirow{2}{*}{$\begin{array}{l}95 \% \text { confidence } \\
\text { interval }\end{array}$} \\
\hline & & No $+\mathrm{V}(\%)$ & Odds Ratio & Z & $\mathrm{P}>|\mathrm{z}|$ & \\
\hline \multicolumn{7}{|c|}{ Consumption of raw milk } \\
\hline Yes & 83 & $22(25.6)$ & 0.10 & 0.91 & 0.317 & $0.31-21.3$ \\
\hline No & 3 & 0 & & & & \\
\hline \multicolumn{7}{|c|}{ Contact with aborted fetus } \\
\hline Yes & 78 & $19(24.4)$ & 2.20 & 0.82 & 0.411 & $0.33-14.8$ \\
\hline No & 8 & $3(35.7)$ & & & & \\
\hline \multicolumn{7}{|c|}{ Touch retained placenta } \\
\hline Yes & 31 & $18(58.0)$ & 10.80 & 5.19 & 0.000 & $4.38-26.3$ \\
\hline No & 55 & $4(7.3)$ & & & & \\
\hline \multicolumn{7}{|c|}{ Drink animal blood } \\
\hline Yes & 73 & $20(27.4)$ & 0.49 & 1.16 & 0.25 & $0.14-1.63$ \\
\hline No & 13 & $2(15.4)$ & & & & \\
\hline \multicolumn{7}{|l|}{ Age } \\
\hline Young & 18 & $2(11.1)$ & & & & \\
\hline Adult & 46 & $12(26.1)$ & 2.10 & 1.52 & 0.126 & $0.29-2.9$ \\
\hline Old & 22 & $8(36.4)$ & 3.40 & 3.21 & 0.030 & $5.4-43.3$ \\
\hline \multicolumn{7}{|l|}{ Sex } \\
\hline Male & 55 & $14(25.5)$ & 1.20 & 0.43 & 0.664 & $0.49-3.02$ \\
\hline Female & 31 & $8(25.8)$ & & & & \\
\hline
\end{tabular}

\section{Discussion}

Confirmed sero-prevalence of brucellosis in small ruminant was $8.8 \%$. This result is closely in agreement with previous serological study result of $9.6 \%$ in Yabello district of Borena zone, southern Ethiopia (Ragassa et al., 2009). On the contrary, this result is higher than previous research result of $4.8 \%$ in Afar region, Eastern Ethiopia (Mohammed et al., 2007), 1.37\% Somali region, Eastern
Ethiopia (Animut et al., 2009), 4.89\% Amhara region, northern Ethiopia (Teshale et al., 2006) and 3.3\% Borena, southern Ethiopia (Sintayehu et al., 2015). This difference between the previous result and current result may be due to study area difference, sampled animal composition and the difference in sensitivity or specificity of the serological test used.

In the present study, the sero-prevalence of human brucellosis were $25.6 \%$ by C-ELISA. The current 
study result recorded is lower than the result recorded of $34.1 \%$ and $29.4 \%$ in Borena and Hamer pastoral area of southern Ethiopia respectively (Animut et al., 2009). The lower prevalence of the current study compared to the previous studies can be explained as variation in the study population; the previous study was conducted on pastoralists with febrile illness. The current study result is higher than most studies conducted in high land areas. This can be explained as higher prevalence is due to difference in the ecosystem and community practice (consumption of raw milk and blood, handling aborted fetus and fetal membrane) which are considered to be the main way of transmission of disease from animals to humans (Mantur and Amarnath, 2008; Animut et al., 2009; Tibeso et al., 2014). Consequently, drinking raw milk and blood, handling aborted fetuses/retained fetal membranes by bare hand, leave/place aborted materials in the environment and touch vaginal discharges while support parturition. This questioner result is in agreement with the study documented (Kassahun et al., 2006; Mussie et al., 2007; Kassahun et al., 2007).

Same of pastoralist in Pastoral Association (PA) complain about the presence of undulant fever, back pain, joint and muscular problem which could be the compatible clinical sign of brucellosis (Teshale et al., 2006; Yohannes, 2012). This implies that there are a large number of undiagnosed cases of febrile diseases, osteoarticular complication (joint problems) and certain generalized complications in pastoral communities that might be associated with brucellosis (Ragassa et al., 2009; Tolosa et al., 2007; Kassahun et al., 2007).

In this study, the challenge encounter was a financial problem to collect sufficient samples or samples with the best representation of Brucellosis situation in community. It was also advantageous to characterize the bacterial species circulating in human and small ruminate as well but I haven't succeeded to do this test due to financial limitations and absence of well-equipped laboratory nearer to study area for zoonotic disease diagnosis and investigation.

\section{Conclusion and Recommendations}

Animals are the main source of Brucella infection for humans. The sero-prevalence recorded in the present study revealed that Brucellosis is a widespread and established disease in small ruminants and humans in the study area. The possibility of Brucellosis seropositivity for humans was contacted with retained fetal membrane and age. In small ruminants, herd size and female animals with a history of the retained fetal membrane are prone to be seropositive relative to other groups of animals. In humans, drinking raw animal blood, handling of aborted fetus and contact with the vaginal discharge of infected animals had not shown statistical significance. Traditional husbandry and poor management practices, the same grazing area of different species of animals, letting aborted material in environment and unrestricted movement of animals were thought to support the spread of the disease between animals as well as a human in the study area. The prevalence of human brucellosis is higher than the prevalence in animals. This could be due to community close contact and ingestion of raw animal products from the single infected animals within whole family members. In conclusion, community close contact with livestock, handling cases with bare hands, consumption of the raw animal product and letting aborted materials in the environment could enhance the spread of disease between animals and humans. Therefore, the disease situation and species of bacteria circulating in the area should be assessed more widely in all animal species and humans to know the transmission dynamics of disease in the animal; and humans.

Awareness creation of public health education on zoonotic importance of brucellosis and prevention techniques should be imparted continuously in the pastoral community.

\section{Acknowledgment}

The authors would like to thank the Director of National Animal Health and Diagnostic and Investigation Centre (NAHDIC), Oromia Pastoralist Area Development Commission and the head of the Molecular Biology of NAHDIC and Bacterial Serology Department for their supports.

\section{Ethics}

Ethical Clearance for animal sampling was obtained from the College of Veterinary Medicine and Agriculture, Addis Ababa University. Whereas human sampling ethical clearance was obtained from the Aklilu Lema Institute of Pathobiology, Addis Ababa University. The same human sample collected from the area was also used for Ph.D. research on Brucellosis from the Borena area.

\section{References}

Amenu, K., E. Thys, A. Regassa and T. Marcotty, 2010. Brucellosis and tuberculosis in Arsi-Negele District, Ethiopia: Prevalence in ruminants and people's behavior towards zoonoses. Tropicultura, 28: 205-210.

Animut, A., Y. Mekonnen, D. Shimelis and E. Ephraim, 2009. Febrile illnesses of different etiology among outpatients in four health centers in north western Ethiopia. Japanese J. Infect. Dis., 62: 107-110. PMID: 19305049 
Habtamu, T.T., B. Richard, H. Dana and A.T. Kassaw, 2015. Camel brucellosis: Its public health and economic impact in Pastoralists, Mehoni District, Southeastern Tigray, Ethiopia. J. Microbiol. Res., 5: 149-156. DOI: 10.5923/j.microbiology.20150505.02

Kassahun, A., P. Shiv, Y. Asfaw, G. Esayas and A. Gelagaye et al., 2007. Seroprevalence of brucellosis in cattle and high risk professionals in Sidama Zone, Southern Ethiopia. Ethiopian Vet. J., 11: 69-84.

Kassahun, J., E. Yimer, A. Geyid, P. Abebe and B. Newayeselassie et al., 2006. Sero-prevalence of brucellosis in occupationally exposed people in Addis Ababa, Ethiopia. Ethiopian Med. J., 44: 245-252.

Mantur, G. and K. Amarnath, 2008. Brucellosis in India, a review. J. Biosci., 33: 539-547. DOI: $10.1007 / \mathrm{s} 12038-008-0072-1$

McDermott, J.J. and S.M. Arimi, 2002. Brucellosis in sub-Saharan Africa epidemiology, control and impact. Vet. Microbiol., 90: 147-156.

DOI: 10.1016/S0378-1135(02)00249-3

Megersa, B., D. Biffa, F. Abunna, A. Regassa and J. Godfroid et al., 2011. Sero-prevalence of brucellosis and its contribution to abortion in cattle, camel and goat kept under pastoral management in Borana, Ethiopia. Tropical Anim. Health Product., 43:651-656. DOI: $10.1007 / \mathrm{s} 11250-010-9748-2$

Mohammed, M., S. Mindaye, Z. Hailemariam, N. Tamerat and Y. Muktar, 2007. Sero-prevalence of small ruminant brucellosis in three selected districts of Somali region, Eastern Ethiopia. J. Vet. Sci. Anim. Husbandry, 5: 2348-9790. DOI: $10.15744 / 2348-9790.5 .105$

Mussie, H., K. Tesfu, T. Mulugeta, B. Kelay and A. Yilkal et al., 2007. Seroprevalence of brucellosis in cattle and occupationally related human in selected sites of Ethiopia. Ethiopian Vet. J., 11: 49-65.

OIE, 2004. Manual of the Diadnostic Tests and Vaccines for Terrestrial Animals. 5th Edn., Office International des Epizooties, Paris, France, pp: 438.

Pappas, G., P. Papadimitriou, N. Akritidis, L. Christou and E.V. Tsianos, 2006. The new global map of human brucellosis. Lancet Infect. Dis., 6: 91-99. DOI: 10.1016/S1473-3099(06)70382-6

Ragassa, G., D. Mekonnen, L. Yamuah, H. Tilahun and T. Guta et al., 2009. Human brucellosis in traditional pastoral communities in Ethiopia. Intern. J. Trop. Med., 4: 59-64.

Shimeles, A., 2008. Sheep brucellosis: Prevalence and its zoonotic impact. MSc Thesis, Addis Ababa University, DebreZeit, Ethiopia.

Sintayehu, G., B. Melesse, A. Abayneh, D. Sintayehu and A. Melaku et al., 2015. Epidemiological survey of brucellosis in sheep and goats in selected pastoral and agro-pastoral lowlands of Ethiopia. Revue Scientifiqueet Technique Office Int. Epizootic Magzine, 34: 881-893. DOI: 10.20506/rst.34.3.2403
Solomon, T.B., H.A. Snyman and G.N. Smit, 2006. Cattle-rangeland management practices and perceptions of pastoralists towards rangeland degradation in the Borana zone of Southern Ethiopia. J. Environ. Manage., 84: 481-494. DOI: $10.1016 /$ j.jenvman.2006.01.008

Terefe, Y., S. Girma, N. Mekonnen and B. Asrade, 2017. Brucellosis and associated risk factors in dairy cattle of eastern Ethiopia. Tropical Anim. Health Product., 49: 599-606. DOI: 10.1007/s11250-017-1242-7

Teshale, S., Y. Muhie, A. Dagne and A. Kidanemariam, 2006. Sero-prevalence of small ruminant brucellosis in selected districts of Afar and Somali pastoral areas of Eastern Ethiopia: The impact of husbandry practice. Revue de Elevage et Medicine Veterinaire des Pays Tropicaux, 157: 557-563.

Tibeso, G., N. Ibrahim and B. Deresa, 2014. Seroprevalence of bovine and human brucellosis in Adami Tulu, Central Ethiopia. World Applied Sci. J., 31: 776-780.

Tolosa, T., F. Ragassa, K. Belihu and G. Tizazu, 2007. Brucellosis among patients with fever of unknown origin in Jimma University Hospital South Western Ethiopia. Ethiopian J. Health Sci., 17: 59-63.

Tsegay, A., G. Tuli, T. Kassa and N. Kebede, 2017. Sero-prevalence and risk factors of Brucellosis in small ruminants slaughtered at Debre - Ziet and Modjo export abattoirs, Ethiopia. J. Infect. Dev. Countries, 9: 373-380. DOI: 10.3855/jidc.4993

Yohannes, G., 2012. Epidemiological investigation of brucellosis in ruminant and human in Yabello district of Borena pastoral area, Oromia national regional state, southern Ethiopia. MSc Thesis, Addis Ababa University College of agriculture and Veterinary Medicine, Bishoftu, Ethiopia.

Zeru, F., W. Gebrezgabher, K. Dessalegn, S. Tilahun and Y. Gubena et al., 2016. Prevalence and risk factor of brucellosis in dromedaries in selected pastoral districts of afar, Northeastern Ethiopia. J. Natural Sci. Res., 6: 1-9. 